\title{
U.S. GEOLOGICAL SURVEY \\ SCIENTIFIC VISUALIZATION WORKSHOP, NEW ORLEANS, LOUISIANA, APRIL 11-12, 1994: PROGRAM AND ABSTRACTS
}

Compiled by Gerry Lebing, Diane C. Brown, and Richard A. MacDonald

U.S. Geological Survey

Open-File Report 94-1

Reston, Virginia

1994 


\title{
DEPARTMENT OF THE INTERIOR
}

\author{
BRUCE BABBITT, Secretary \\ U.S. GEOLOGICAL SURVEY \\ Gordon P. Eaton, Director
}

Cover design by Sharon Cline and Pamela Fultz.

Any use of trade, product, or firm names is for descriptive purposes only and does not imply endorsement by the U.S. Government.

For additional information write to:

U.S. Geological Survey

Information Systems Division

Branch of Technical Assessment

804 National Center

Reston, Virginia 22092
Copies of this report can be obtained from:

U.S. Geological Survey USGS ESIC-Open File Report Section

Box 25286, MS 517

Denver Federal Center

Denver, Colorado 80225-0046 


\section{FOREWORD}

In a letter to Jacques Hadamard, Albert Einstein wrote:

The words or the language, as they are written or spoken, do not seem to play any role in my mechanism of thought. The psychical entities which seem to serve as elements in thought are certain signs and more or less clear images which can be "voluntarily" reproduced and combined...this combinatory play seems to be the essential feature in productive thought before there is any connection with logical construction in words or other kinds of signs which can be communicated to others.

Clearly, Dr. Einstein realized the value of visualization for the sciences. During this workshop, you will see and hear ample evidence that the U.S. Geological Survey has embraced scientific visualization tools and techniques to aid investigations into earth science problems and communicate results to the global community. The collection of abstracts presented herein summarize the experiences of investigators within the U.S. Geological Survey, as well as colleagues external to the organization. Previous workshops were held at Norfolk, Virginia, in May, 1992, and at Menlo Park, California, in September, 1993.

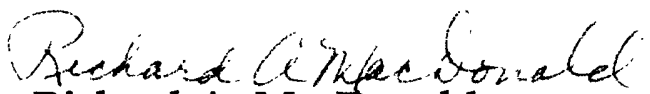




\section{CONTENTS}

Foreword $\ldots \ldots \ldots \ldots \ldots \ldots \ldots \ldots \ldots \ldots \ldots \ldots \ldots \ldots \ldots \ldots$

Program $\ldots \ldots \ldots \ldots \ldots \ldots \ldots \ldots \ldots \ldots \ldots \ldots \ldots$ vii

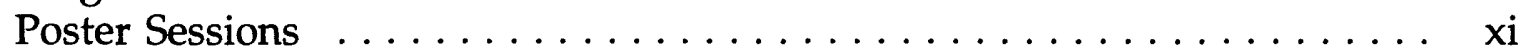

Abstracts

Color Techniques for Effective Scientific Visualizations

Michael J. Bailey ........................ 1

Poor Man's Visualization of Venus or Terrain Animation for the

Economically Challenged

Janet M. Barrett, Laurence A. Soderblom, Randolph L. Kirk,

and Mary G. Chapman ....................... 2

Volume Visualization: Just the Beginning

Eric Bayer ...........................

Infobase: A Multimedia Data Environment

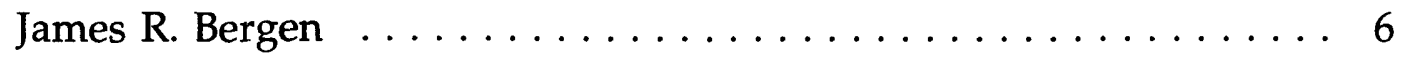

Using Geographic Information, Image Processing, and Animation

Systems to Visualize a Digital Terrain Flyby

Robert G. Clark, John W. Jones, Thomas E. Ciciarelli, and Daniel F.

Stanfill IV ......................... 7

Geographic Information System in an Electronic Meeting Environment

with Application to Land Resource Allocation Issues

Brenda G. Faber, Raymond D. Watts, William W. Wallace,

Jacob E. Hautaluoma, and Jef Knutson . . . . . . . . . . . . . 8

Video Capabilities Provided by the U.S. Geological Survey Scientific

Visualization Laboratory

Carmelo F. Ferrigno and Brian R. Schachte . . . . . . . . . . . 10

Environmental Data Visualization: Issues and Lessons

Kevin J. Hussey . . . . . . . . . . . . . . . . . . . . 12

A Temporal Comparison of Forest Cover Using Digital Earth Science

Data and Visualization Techniques

John W. Jones . . . . . . . . . . . . . . . . . . 13 
National Information Display Laboratory Overview

Mark J. Lister ......................... 14

An Animated Three-Dimensional Visualization of the Geologic and

Bathymetric Features Surrounding Isla de Mona, Puerto Rico

Luis E. Menoyo ............................ 16

Mosaic: A Tool for Presenting U.S. Geological Survey Visualizations on the Internet

William G. Miller . . . . . . . . . . . . . . . . . 17

Extending the Dimensions of Data Visualization

Terry J. Myerson. . . .................... 18

Visualization of a Structural Model of Äspö, Sweden

Mary E. Powell, Wesley A. Gurney, Steven S. Bong, and

Clifford Voss. . . . . . . . . . . . . . . . . . . . . . . . 19

The Realities of Visualizing Earth Sciences Data

Theresa M. Rhyne. . . . . . . . . . . . . . . . . . . . 21

How to Construct and View Computer-Generated Animation

Sequences on your Workstations: Shareware Tools or Working with

Compression Files

Richard P. Signell . . . . . . . . . . . . . . . . 22

Issues in the Visualization of Large Terrain Databases

Daniel F. Stanfill IV. . . . . . . . . . . . . . . . . . . 23

Visualizing Geographic Data: Integrating a Geographic Information System and Scientific Visualization System

Mary Stephenson. . . . . . . . . . . . . . . . . . . . 24

Application of Scientific Visualization Techniques for Analysis of the 1993 Flood on the Mississippi River

Lisa M. Traub. . . . . . . . . . . . . . . . . . . . . 25

Developing a Three-Dimensional Hydrogeologic Model

A. Keith Turner, Claudia C. Faunt, and Frank A. D'Agnese. . . . . . 26

GeoMedia2: A Multimedia Educational System on Global

Environmental Change for Middle School Students

Denise A. Wiltshire and Carmelo F. Ferrigno. 
Visualization of Marine Scientific Data

Evelyn L. Wright, Richard P. Signell, and Dwight F. Coleman. . . . 31

Using Scientific Visualization Techniques to Portray Land Surfaces

Paul M. Young. ...................... 32 


\title{
PROGRAM \\ U.S. Geological Survey \\ Scientific Visualization Workshop
}

\author{
Clarion Hotel \\ New Orleans, Louisiana \\ April 11-12, 1994
}

Sunday, April 10, 1994

4:00 pm - 8:00 pm Registration

Monday, April 11, 1994

8:00 am - 10:00 am

The Combined NCTM/SVW Opening Session

10:00 am - 10:30 am

Break

10:30 am - 10:35 am

Welcome, Richard A. MacDonald, U.S. Geological Survey

10:35 am - 11:05 am

Color Techniques for Effective Scientific Visualizations,

Michael J. Bailey, San Diego Supercomputer Center

11:05 am - 11:35 am

Visualization of Marine Scientific Data, Evelyn L. Wright,

U.S. Geological Survey

11:35 am - 12:05 pm

Using Geographic Information, Image Processing and Animation

Systems to Visualize a Digital Terrain Flyby, Robert G. Clark, U.S. Geological Survey

12:05 pm - 1:30 pm

Lunch 
1:30 pm - 2:00 pm

The Realities of Visualizing Earth Sciences Data, Theresa M. Rhyne,

U.S. Environmental Protection Agency

2:00 pm - 2:30 pm

Developing a Three-Dimensional Hydrogeologic Model, A. Keith

Turner, U.S. Geological Survey

\section{2:30 pm - 3:00 pm}

A Temporal Comparison of Forest Cover Using Digital Earth Science Data and Visualization Techniques, John W. Jones, U.S. Geological Survey

3:00 pm - 3:30 pm

Break

3:30 pm - 4:00 pm

Application of Scientific Visualization Techniques for Analysis of the 1993 Flood on the Mississippi River, Lisa M. Traub, U.S. Geological Survey

4:00 pm - 4:30 pm

Visualizing Geographic Data: Integrating a Geographic Information System and Scientific Visualization System, Mary Stephenson, North Carolina Supercomputing Center

4:30 pm - 5:30 pm

Panel Discussion: Visualization Facilities Available at the U.S. Geological Survey

Tuesday, April 12, 1994

8:00 am - 8:30 am

Volume Visualization: Just the Beginning, Eric Bayer, Intergraph Corporation

8:30 am - 9:00 am

National Information Display Laboratory Overview, Mark J. Lister, National Information Display Laboratory 
9:00 am - 9:30 am

How to Construct and View Computer-Generated Animation Sequences on your Workstations: Shareware Tools for Working with Compression Files, Richard P. Signell, U.S. Geological Survey

9:30 am - 10:00 am

Video Capabilities Provided by the U.S. Geological Survey Scientific Visualization Laboratory, Carmelo F. Ferrigno, U.S. Geological Survey

10:00 am - 10:30 am

Break

10:30 am - 11:00 am

Issues in the Visualization of Large Terrain Databases, Daniel F.

Stanfill IV, Jet Propulsion Laboratory

11:00 am - 11:30 am

Using Scientific Visualization Techniques to Portray Land Surfaces, Paul M. Young, U.S. Geological Survey

11:30 am - 12:00 noon

An Animated Three-dimensional Visualization of the Geologic and Bathymetric Features Surrounding Isla de Mona, Puerto Rico, Luis E. Menoyo

12:00 noon - 1:30 pm

Lunch

1:30 pm - 2:00 pm

Environmental Data Visualization: Issues and Lessons, Kevin J. Hussey, Jet Propulsion Laboratory

2:00 pm - 2:30 pm

Mosaic: A Tool for Presenting U.S. Geological Survey Visualizations on the Internet, William G. Miller, U.S. Geological Survey

2:30 pm - 3:00 pm

Geographic Information System in an Electronic Meeting Environment with Application to Land Resource Allocation Issues, Raymond D.

Watts, U.S. Geological Survey

3:00 pm - 3:30 pm

Break 
3:30 pm - 4:00 pm

Extending the Dimensions of Data Visualization, Terry J. Myerson, Kubota Pacific Computer

4:00 pm - 4:30 pm

Infobase: A Multimedia Data Environment, James R. Bergen, National Information Display Laboratory

4:30 pm - 5:00 pm

GeoMedia2: A Multimedia Educational System on Global

Environmental Change for Middle School Students, Denise A. Wiltshire, U.S. Geological Survey 


\section{Posters for \\ U.S. Geological Survey Scientific Visualization Workshop}

Poor Man's Visualization of Venus or Terrain Animation for the Economically Challenged

Janet M. Barrett, U.S. Geological Survey; Laurence A. Soderblom, U.S. Geological Survey; Randolph L. Kirk, U.S. Geological Survey;

Mary G. Chapman, U.S. Geological Survey

Visualization of a Structural Model of Äspö, Sweden

Mary E. Powell, U.S. Geological Survey; Wesley A. Gurney,

U.S. Geological Survey; Steven S. Bong, Camber Corporation; Clifford

Voss, U.S. Geological Survey 


\section{Color Techniques for Effective Scientific Visualizations}

Bailey, Michael J., Manager, Scientific Visualization, San Diego Supercomputer Center, P.O. Box 85608, San Diego, CA 92186-9784

The trend toward larger and larger data sets in fields such as earth science has generated a need in the scientific visualization community for more effective visualization techniques. Even with the best of techniques, the amount of data being displayed in a typical visualization can easily overwhelm the viewer and provide more confusion than elucidation.

One of the most traditional techniques for expanding the informational content of scientific visualizations is the use of color. Proper use of color can increase the amount of information which can be displayed, redundantly enhance information already being displayed, or emphasize certain key features of the data.

But, unless used with careful forethought, color can also detract from image display rather than enhance it. This presentation will discuss rules-of-thumb in using color to enhance scientific visualizations. Topics will include specifying color, avoiding bad contrasts using meaningful color scales, employing ways to fool the eye with color and how to avoid them, avoiding certain colors and color combinations, using color gamuts, and considering videotape topics. Included will be both good and bad examples of color usage. 


\section{Poor Man's Visualization of Venus or Terrain Animation for the Economically Challenged}

Barrett, Janet M., U.S. Geological Survey, Buildings 4\&5, 2255 North Gemini Drive, Flagstaff, AZ 86001-1698;

Soderblom, Laurence A., U.S. Geological Survey, Building 1, 2255 North Gemini Drive, Flagstaff, AZ 86001-1698;

Kirk, Randolph L., U.S. Geological Survey, Buildings 4\&5, 2255 North Gemini Drive, Flagstaff, AZ 86001-1698;

Chapman, Mary G., U.S. Geological Survey, Buildings 4\&5, 2255 North Gemini Drive, Flagstaff, AZ 86001-1698

A commonly used scientific visualization technique, the animated terrain flyover is produced by perspective rendering of a series of views of an image data set "draped" over a topographic model. Then these views are played at high speed on a video display. To date, a scientist wishing to make use of this technology for studying a planetary surface has had two basic options:

1) Investing $\$ 100,000$ or more either in a very high performance graphics workstation that is capable of rendering flyovers in real time or in a lower performance workstation that has video-recording hardware to capture frames rendered more slowly and then obtaining animation software and learning to use it (or developing such software from scratch). After this investment of money and time, the scientist can pick flight paths and make animations that show precisely the features of greatest interest.

2) Obtaining videotapes of animation sequences created by someone else who has a high performance workstation. These sequences may or may not show what is of most interest to the scientist in question.

Our goal is to provide the scientist-user with a third option that provides flexibility in constructing animations that show the features of interest, yet does not require expensive computer hardware. Our approach is to use a high performance workstation and software to render a large number of perspective views and to record these frames on a compact disk (CD). A scientist can then design and view animation sequences using only an inexpensive desktop computer or workstation with a CD drive and a grayscale display and one of the many software packages that 
can display sets of images sequentially as "movies." This is accomplished by selecting a subset of the multiparameter image set on $C D$, varying the vantage point, exaggeration, and so on, and loading the frames into memory, from where they can be displayed.

This approach obviously offers less flexibility than running one's own visualization software. The limited number of rendered frames that can be stored, even on a CD, precludes supplying the user with enough choices to make arbitrary flyovers. Instead, our approach supplies frames that can be assembled into sequences in which the terrain rotates, tilts, and zooms in front of the viewer. Nevertheless, this intermediate level of animation capability could be of real use to scientists who do not have access to high performance computers. In the future, CDs containing rendered image sets of a given map quadrangle could be included among the supplementary data sets supplied to planetary geologic mappers.

Our demonstration uses Magellan image and elevation data for Venus. The image base was taken from the Galindo $\left(\mathrm{V} 40 ; 0^{\circ} \mathrm{S}-25^{\circ} \mathrm{S}, 240^{\circ} \mathrm{E}-270^{\circ} \mathrm{E}\right.$ ) quadrangle of the 1:5,000,000-scale map series, the base maps for the Venus Geologic Mapping Program (Batson, Kirk, Morgan, in press). The image was enhanced by spatial filtration, contrast exaggeration, and the addition of relief shading, as described by Kirk and others (1992). Elevation data from the Magellan global altimetric data set (GTDR) (Pettengill, and others, 1991) were merged with pre-Magellan data to fill gaps, reprojected to register to the image, and smoothed at the resolution of the altimeter. Rendering was performed on a SUN SPARCstation 10 model 512 with the Surveyor software package. The images were transferred to a VAX computer and written to a CD write-once disk in Vicar format. A different format (e.g., PDS-compliant) could be adopted for the future production of disks to meet scientific needs. Our demonstration will be performed using NIH Image software on a Macintosh computer.

\section{Selected References:}

Batson, R.M., Kirk, R.L., and Morgan, H.F., Cartography of Venus, Photogrammetric Engineering and Remote Sensing (in press).

Kirk, R.L., Soderblom, L.A., and Lee, E.M., 1992, Enhanced visualization for interpretation of Magellan radar data: Supplement to the Magellan Special Issue, Journal of Geophysical Research, v. 97, no. 10, pt. E, p. 16,371-16,380.

Pettengill, G.H., Ford, P.G., Johnson, W.T.K., Raney, R.K., and Soderblom, L.A., 1991, Magellan radar performance and data products: Science, v. 252, p. 260-265. 


\section{Volume Visualization: Just the Beginning}

Bayer, Eric, Intergraph Corporation, Huntsville, AL 35894-0001

Volume visualization is the display of three-dimensional (3D) geoscientific models. It is a new topic of discussion in the world of geographic information systems (GIS). Volume visualization is a newly evolving science that is currently at the same point that GIS was 15 years ago when the ability to display two-dimensional (2D) graphics on a map in different colors was considered "high tech." Today, GIS includes sophisticated spatial analysis tools that handle both raster and vector data. Extending these analysis tools to handle volume data is the next logical step in the evolution of GIS.

Several vendors are starting to offer visualization packages, either as programming languages or as standalone systems that interface to other modeling packages, but full integration with GIS is seldom achieved. With today's increases in the speed and functionality of computer graphics hardware and software, visualization of 3D models has become a common means of showing volume data to both technical and non-technical people. Volume visualization is often relegated to being just the pretty picture used to wrap-up a project. However, serious analysis and interpretation of $3 \mathrm{D}$ volumes are possible with newer software products. These products allow the scientist to interactively analyze and manipulate volume data. Such tools are valuable because people tend to take the results of the numerical models at face value and in the past have had no ability to include manual adjustments if the results do not accurately reflect reality. Further development of interactive control techniques and more sophisticated displays will be the next logical step after volume visualization.

This presentation will review and discuss some basic 3D analysis concepts. The need to geo-reference sample data within a defined volume is essential. Cross-plots of data values allow intelligent data validation prior to creating a full digital model. For example, an environmental scientist may want to cross-plot a contaminant with z-elevations to verify inconstancy of data in the z-domain. Then displaying anomalous data inside the $3 \mathrm{D}$ volume will increase the user's confidence in the validity of the data. Visual analysis beyond rendering a single attribute within a volume is also important. The ability to analyze and model multi-variable problems (such as multiple contaminants) is a powerful feature for improving the understanding of complex situations and gives the scientist insight into the 
relationships between attributes that may otherwise go unseen. Boolean operations between volumes are also important analysis techniques which will allow the scientist to create complex queries on volume data. The following is one example of using Boolean operations to query the data: "Find and calculate the volume with porosity greater than 6 percent and permeability greater than 10 percent within a geologic layer and show the result colored coded with permeability values." Finally, because the results of pure numeric models may not be what the scientists expect based on experience at a specific site, interactive volume interpretation is a necessity.

It is the development of volume visualization tools like these that will allow scientists to explore the true nature of solid volumes representing geoscientific phenomena. 


\section{Infobase: A Multimedia Data Environment}

Bergen, James R., David Sarnoff Research Laboratory, National Information Display Laboratory, P.O. Box 8619, Princeton, NJ 08543-8619

Infobase is a multimedia data environment based on an information organization, a database, and an interactive software application toolset that is generally applicable to projects in which users analyze multiple source remotely sensed data together with ancillary information. Enabling technologies include multisensor and multitemporal registration, temporal and spatial feature extraction, object based design, and an object oriented database. The initial application of Infobase is to land characterization projects at the U.S. Geological Survey, Earth Resource Observation Systems (EROS) Data Center. The applicability of the project extends to cooperative work between civil and defense communities. Infobase is funded as a dual use project sponsored by the Office of Research and Development. 


\section{Using Geographic Information, Image Processing, and Animation Systems to Visualize a Digital Terrain Flyby}

Clark, Robert G., U.S. Geological Survey, 804 National Center, Reston, VA 22092; Jones, John W., U.S. Geological Survey, 521 National Center, Reston, VA 22092; Ciciarelli, Thomas E., U.S. Geological Survey, 526 National Center, Reston, VA 22092;

Stanfill IV, Daniel F., Visualization and Earth Science Applications Group, Image Processing Applications and Development Section, Jet Propulsion Laboratory, California Institute of Technology, 4800 Oak Grove Drive, Pasadena, CA 911098099

Many researchers are finding it difficult to procure expensive analytical software because of decreasing government and university funding. Therefore, this multidivisional, multiagency project focused on integrating commercial software $(\mathrm{ARC} / \mathrm{INFO})^{\mathrm{TM}}$, free software (Khoros) ${ }^{\mathrm{TM}}$, and inexpensive software (Surveyor) to merge several data sets and produce terrain flybys. The merged data sets include a digital orthophoto quadrangle (DOQ) image, a digital elevation model data set, and the transportation and hydrography digital line graph (DLG) data layers. To process these data sets in the desired manner, software was integrated using ARC/INFO, Khoros, and Surveyor. Image registering and resampling were performed with a copy of ARC/INFO, a geographic information system. Two ancillary Khoros routines were constructed that facilitate importing ARC/INFO formatted data to Khoros and exporting Khoros formatted data to Surveyor. With the merging of ARC/INFO DOQ and DLG images, Khoros was used to produce red, green, and blue images that were used as input to Surveyor. The Jet Propulsion Laboratory's inexpensive Surveyor software was then used to produce several DOQ and DLG terrain flybys. In using this project's approach, not only were the best features of each of the individual software applications exploited, but also money was saved by integrating existing commercial, free, and inexpensive analytical software. 


\section{Geographic Information System in an Electronic Meeting Environment with Application to Land Resource Allocation Issues}

Faber, Brenda G., Consortium for International Earth-Science Information Network (CIESIN)/TERRA Laboratory, 315 West Oak Street, Suite 101, Fort Collins, CO 80521;

Watts, Raymond D., U.S. Geological Survey/TERRA Laboratory, 315 West Oak Street, Suite 101, Fort Collins, CO 80521;

Wallace, William W., CIESIN/TERRA Laboratory, 315 West Oak Street, Suite 101, Fort Collins, CO 80521;

Hautaluoma, Jacob E., Department of Psychology, Colorado State University, Fort Collins, CO 80521

Knutson, Jef, Department of Psychology, Colorado State University, Fort Collins, CO 80521

TERRA Lab -- the Terrestrial Ecosystems Regional Research and Analysis Laboratory -- is applying the active response geographic information system (GIS) to studies of regional land resource issues in the western United States. TERRA Lab is supported by the U.S. Department of Agriculture (Agricultural Research Service, Forest Service, and Soil Conservation Service), the U.S. Department of the Interior (U.S. Geological Survey and Bureau of Mines), the Environmental Protection Agency, and the Consortium for International Earth-Science Information Network (CIESIN). TERRA Lab is located in Fort Collins, Colorado.

TERRA Lab has merged the technologies of the electronic meeting environment and the GIS to produce an "Active Response GIS." This technology allows meeting participants to visualize geographic information, to interact with it in forming and expressing opinions about land-management issues, and to visualize the results of group analysis.

Electronic meeting environments are based on a cluster of workstations (laptop computers in this implementation), a file server, and a facilitator's control station, which are installed in a room to accommodate 5 to 15 participants. These environments are most frequently applied in business management, where groups can accomplish tasks such as brainstorming, setting priorities of goals or tasks, and developing consensus. The environment allows personal interaction and the anonymous expression of ideas and opinions through computers and software tools. Anonymity contributes to effective meetings by ensuring that group opinions are represented in the outcome, rather than opinions of dominant participants only. 
Another advantage of the environment is that documentation of meeting results is available immediately.

The active response GIS adds to the capabilities of the electronic meeting environment by providing facilities for data display and interaction. Meeting participants can individually select from a menu of GIS layers and can draw polygons that express their spatial opinions about land resource issues. They might, for example, indicate areas that they favor for protection or for a proposed use. Participants can select any data layer; previously digitized polygons are shown on the newly selected layer.

The system copies the digitized polygons to the facilitator's workstation, where the polygons are combined into derivative spatial data layers. One useful product, for example, is the depiction of the number of participants' polygons that overlap at any point. The group can use this product to identify areas where concensus exists to include or exclude land for the given purpose; focus can also be placed on analyzing and discussing those areas where agreement is lacking. 


\section{Video Capabilities Provided by the U.S. Geological Survey Scientific Visualization Laboratory}

Ferrigno, Carmelo F., U.S. Geological Survey, Information Systems Division, 804 National Center, Reston, VA 22092;

Schachte, Brian R., U.S. Geological Survey, Information Systems Division, 804 National Center, Reston, VA 22092

U.S. Geological Survey (USGS) scientists evaluate and develop tools for the visualization of scientific data. One important goal is to determine suitable media for presenting visualizations to the scientific community and the general public. The principal media include slides, transparencies, computer-based presentations, compact discs, and videotapes. Videotape provides a commonly used and costeffective medium for disseminating earth science information, especially in the form of animations or video.

The process of producing a presentation-quality videotape from computer-generated animations involves several tasks. The three major steps in the videotape production process are animation creation, animation recording, and videotape postproduction. This process assumes that the scientist has previously generated the data and/or model that will be visualized. The videotape examples were produced at the USGS Scientific Visualization Laboratory (Laboratory) located at the National Center in Reston. The purpose of assessing the video production process is to become familiar with the techniques for producing videos and to determine if it is feasible for USGS scientists to use the Laboratory equipment to produce video-based presentations.

The animations can be created on UNIX, Apple ${ }^{\circledR}$ Macintosh ${ }^{\circledR}$, or DOS-based systems. In the Laboratory, the principal UNIX-based animation and image processing packages are AVS $^{\mathrm{TM}}$ by Advanced Visual Systems, Inc., Khoros ${ }^{\circledR}$ developed at the University of New Mexico, and Surveyor developed by the Jet Propulsion Laboratory. Macintosh software includes three-dimensional modeling software and multimedia authoring tools such as Macromedia ${ }^{\circledR}$ Director ${ }^{\mathrm{TM}}$. The DOSbased software includes Topas ${ }^{\mathrm{TM}}$ by Truevision and 3D Studio ${ }^{\mathrm{TM}}$ and Animator Pro ${ }^{\mathrm{TM}}$ from Autodesk ${ }^{\circledR}$.

Real-time and frame-accurate video recording capabilities are available on Silicon Graphics ${ }^{\circledR}$, Macintosh, and DOS-based systems. Frame-accurate recording is used to place high-resolution animations on videotape. Due to the time involved in creating 
a frame-accurate recording, this process is usually used to create a broadcast-quality videotape suitable for publication and distribution. The frame-accurate recordings are produced in U-Matic SP format. Real-time recording is used to create videotapes of work in progress and is a suitable technique for informal presentations. The videotape formats available for recording in the Laboratory are U-Matic SP (3/4"), S-VHS, and VHS.

The final and most difficult step in this process is video postproduction. The main steps include (1) videotape editing, (2) titling, and (3) adding and editing audio (narration, sound effects, and music). The postproduction process can be time consuming and requires some knowledge and skills that USGS scientists may not possess so they will most likely require specialized video training.

The principal device used for video postproduction in the Laboratory is a Commodore Amiga ${ }^{\mathrm{TM}}$ computer equipped with a NewTek Video Toaster ${ }^{\mathrm{TM}}$. The Video Toaster provides functions such as broadcast-quality titling and transitional effects. This system is used to control all steps in the postproduction process.

Results of the assessment study show that it is possible to produce presentationquality videotapes with the computer and video hardware available in the Laboratory. In addition to access to specialized video-production equipment, the Laboratory provides the following services to USGS scientists:

(1) Analysis of data sets to determine the appropriate computer system and software for creating the data visualizations, and

(2) Assistance in using video-recording equipment.

The Laboratory is not providing video postproduction services at this time. Although the benefits of using videotape for presenting scientific visualizations are clear, video production is time consuming and formal training is needed. USGS scientists must decide whether to produce their own video products or contract with a commercial firm. Commercial video production can be expensive, but the scientist's time may be more valuable. 


\section{Environmental Data Visualization: Issues and Lessons}

Hussey, Kevin J., Technical Group Supervisor, Visualization and Earth Science Applications Group, Jet Propulsion Laboratory, 4800 Oak Grove Drive, Pasadena, CA 91109-8099

Remember the book "How To Lie With Statistics" by D. Huff? If you can lie with statistics, then just imagine what you could do with Data Visualization! It probably has occurred to most of you that viewers of these complex and sometimes very realistic looking visualizations may be "seeing" things that are not supported by the data. This is worrisome when one considers that not all people with computers are as honest as you are. Even well-intentioned practitioners could lend credibility to totally incredible data. Should we do something about this?

\section{A Lesson:}

No matter how good, flexible, extensible, comprehensive, powerful or expensive your visualization system (hardware and software) is, it may not perform exactly what you want. You may have to modify the code to make some things happen.

The Jet Propulsion Laboratory's (JPL's) Digital Image Animation Laboratory (DIAL) and the associated Visualization and Earth Science and Applications (VESA) Group have produced a number of notable environmental visualizations over the past 12 years. Visualization topics have encompassed submarine geology in the Monterey Bay to the Ozone "hole" over Antarctica. The visualization media that were used have been $16 \mathrm{~mm}$ through IMAX to $8 " \times 10$ " color film and from NTSC to HDTV video formats. Scientific data resolutions have ranged from one angstrom to 345 miles. During the course of producing these visualizations, several lessons have been learned, difficult issues raised, and new technology developed. The talk will address some of the issues raised and lessons learned. 


\section{A Temporal Comparison of Forest Cover Using Digital Earth Science Data and Visualization Techniques}

Jones, John W., U.S. Geological Survey, 521 National Center, Reston, VA 22092

Increased demands on forest resources and the recognition of old-growth forests as critical habitats and purifiers of the atmosphere have stimulated attention to forest harvest practices in the United States and worldwide. Visualization technology provides a means by which a history of forestry activities may be documented and presented to the public and decision makers. In this project, Landsat multispectral scanner and thematic mapper images, acquired July 7, 1981, and July 8, 1991, respectively, were georeferenced, resampled, enhanced, and draped over U.S. Geological Survey 30-meter digital elevation models. These data then were used to create perspective views of portions of Mt. Hood Forest, Oregon. The flyby animation (produced by rapidly displaying a sequence of these perspective views) conveys the forest cover change resulting from forest harvest activities over the 10year period. This project shows the value of combining satellite data with base cartographic data and earth science information for use in public education and decision-making processes. 


\section{National Information Display Laboratory Overview}

Lister, Mark J., Director, NIDL Operations, David Sarnoff Research Laboratory, P.O. Box 8619, Princeton, NJ 08543-8619

The National Information Display Laboratory (NIDL) consists of projects in advanced display systems and softcopy tools that enable collaboration. Softcopy tools are tools to process data in electronic form which is opposed to hardcopy film or paper based processing. This presentation will discuss current activities in both program areas.

NIDL Softcopy Tools and Collaboration Overview

Information analysts are confronted by the need to process massive volumes of diverse types of data, ranging from imagery to text and signals. Softcopy tools are useful in screening and establishing information priorities based upon recognition of significant patterns in the data. The tools must be accurate, easy to use, and interactive for analysts to facilitate their ability to share multimedia data, tools, simulations, and expertise with other analysts.

Under the NIDL softcopy tools and collaboration program, recent advancements in softcopy technology are being employed in application domains of current interest to the government. The components of the softcopy tools program are a multimedia data environment known as Infobase and large distributed databases, advanced signal processing, digital data compression, workstation operator identification, and the human-machine interface.

\section{NIDL Advanced Display Systems Overview}

In this era of changing national priorities, the scientific community is expected to exploit increasing volumes of diverse information with fewer resources. To meet this challenge, the information must be presented in an optimally exploitable display format. An additional means to increase analyst efficiency is through the widespread use of distributed collaborative environments, but this also places exacting demands on display performance to assure that the information displayed at distributed locations is equally exploitable.

To provide the scientific community with the softcopy displays needed for the diverse demands of different exploitation problems, the NIDL is working on two 
display technology program tasks: (1) display development, and (2) display modeling and quality control. The goal of the display development task is to improve, develop, and commercialize display technologies for use in softcopy exploitation. The goal of the display modeling and quality control task is to assist the community in the specification, procurement, and operation of softcopy systems. In addition, this program is developing industry standards for display measurement and specification. 


\section{An Animated Three-Dimensional Visualization of the Geologic and Bathymetric Features Surrounding Isla de Mona, Puerto Rico}

Menoyo, Luis E., U.S. Geological Survey, Water Resources Division, GPO Box 44424, San Juan, Puerto Rico 00936

Tecplot, a data visualization software package for the Data General AViiON platform, was used to develop a three-dimensional animated visualization of Isla de Mona, Puerto Rico, located in the Mona Passage about 60 kilometers west of Puerto Rico. The data set was extracted from U.S. Geological Survey geology and marine geology maps of Isla de Mona, Puerto Rico. The ARC/INFO geographic information system software package was used to digitize the bathymetric and topographic contours. This coverage was imported into AutoCAD, and a XYZ coordinate file in ASCII format was then extracted using the Quicksurf module. The ASCII data set was converted into a Tecplot native file using Tecplot's Preplot routine. The Tecplot native file was then used to create a high density three-dimensional regular grid within Tecplot. This regular grid can be used to rotate viewing angle, vary the distance to the grid, and change the geometry and vertical exaggeration. Lighting, type of shading, and color can be chosen to highlight important features in the threedimensional model. Several routines included in the Tecplot software package can be used to run the software in batch mode, simplifying the production of an animated visualization frame. Once the set of frames required for the animation is generated, the user can use Tecplot's Framer routine to display them on the workstation screen. Simple visual cues can be used to draw attention to key features in the visualization.

These animated visualization techniques can be used to develop a better understanding of the natural forces that affect Isla de Mona through time. For example, by changing the elevation parameters of an equal elevation grid to simulate changes in sea level, it is possible to model past changes in precipitation and climate on Isla de Mona due to changes in the relative elevation of the island plateau above sea level. 


\section{Mosaic: A Tool for Presenting U.S. Geological Survey Visualizations on the Internet}

Miller, William G., U.S. Geological Survey, Geologic Division, 915 National Center, Reston, VA 22092

Mosaic is a program written at the National Center for Supercomputing Applications at the University of Illinois, Urbana-Champaign. Mosaic is able to use images, text, audio, animation, and specialized scientific data files to present complex ideas to users of the worldwide Internet. Internet is a computer network comprised of over 20,000 interconnected networks serving over two million computers.

The U.S. Geological Survey (USGS) has developed an experimental service that provides information about USGS research activities and some USGS data products to users of the Mosaic program. The service currently provides information to more than 6,000 users per month who make over 300,000 connections.

Users of Mosaic see the information presented as screens of text and full color images. Certain highlighted areas on the screen may be selected by use of a mouse pointer. Selecting one of these active areas will result in a new screen of information being displayed. The information includes a limited number of fact sheets, publications, data sets, and results of scientific visualization efforts. A registry of other science resources on the Internet is maintained for the use of USGS researchers and the public. The experimental USGS service is available to anyone with a direct connection to the Internet by contacting the computer at info.er.usgs.gov using the Mosaic program. It is expected that this type of service will expand in the future. 


\section{Extending the Dimensions of Data Visualization}

Myerson, Terry J., Technical Consultant, Kubota Pacific Computer, 12030 Sunrise Valley Drive, Suite 180, Reston, VA 22091

Less than 5 years ago, the technical computing community was wild about static-color-contour plots. Today, with new visualization workstations, this same enthusiasm can be obtained with three-dimensional (3D) isosurfaces, particle advections, and volume renderings animated to videotape. This talk will explore the transition from two-dimensional (2D) to 3D to four-dimensional data visualization using both public domain (Vis-5D) and commercially available software (Application Visualization System).

The talk will include demonstrations of interactive visualization, including several pointers on methods to maximize the throughput of the visualization process. A single atmospheric data set will be diced, sliced, convoluted, and animated, with emphasis made upon the new insight to be gained by each new technique along the way. 


\section{Visualization of a Structural Model of Äspö, Sweden}

Powell, Mary E., U.S. Geological Survey, Information Systems Division, 804 National Center, Reston, VA 22092;

Gurney, Wesley A., U.S. Geological Survey, Information Systems Division, 804 National Center, Reston, VA 22092;

Bong, Steven S., Camber Corporation, 2905 Westcorp Boulevard, Suite 216, Huntsville, AL 35805;

Voss, Clifford, U.S. Geological Survey, Water Resources Division, 431 National Center, Reston, VA 22092

A nuclear waste and fuel management laboratory is being constructed 500 meters underground on the island of Äspö, Sweden, by the Swedish Nuclear Fuel and Waste Management Company. The Swedish Nuclear Power Inspectorate will evaluate the effectiveness of geologic and geophysical methods leading to a conceptual tectonic model of the area. Maps and three-dimensional (3D) computer models that will contribute to this evaluation are used in a visualization of the spatial distribution of tectonic discontinuities in the island's bedrock.

A regional map covers a 35x25 kilometer study area of Sweden and two 3D models cover a $2 \times 2 \times 1$ kilometer area of Äspö. One of the 3D models illustrates the configuration of Äspö's fracture zones while the other shows a framework of extensive and discrete fractures transecting the island. These models are based on geological and geophysical primary research data. This fracture data is being interactively modified and refined in relation to hydrogeological, hydrochemical, and rock quality data collected by surface fracture mapping, core logs, and geophysical borehole measurements.

Application Visualization System (AVS), a software package by Advanced Visual Systems, Inc., is being used to visualize the map and 3D models. AVS program modules are used to read a surface fracture map of Äspö in DXF (AutoCAD Drawing Interchange File) format; read the coordinate geometry of the fractures and fracture zones; read the coordinate geometry and geophysical log data of the boreholes; associate the low to high values of the hydrogeological, hydrochemical, and rock quality data with a color scale; and display the resulting 3D models.

Scientists may use AVS interactively to visualize geophysical log data within a structural model. The AVS geometry viewer module may be used to identify specific 
boreholes and fractures. AVS object properties such as transparency or color may be modified to improve the visualization of these boreholes and fractures. These capabilities enable scientists to confirm geographic coordinates of fractures by observing intersections of fractures and geophysical attributes (seen as changes in color) along the boreholes.

Intergraph and Dynamic Graphics visualization software packages are being used simultaneously by Swedish scientists and at U.S. Geological Survey to complete models of the same fracture structure. A future comparison will be made to evaluate the resulting AVS models. Techniques used within AVS to develop this experimental visualization of Äspö, Sweden, have applicability in other geologic studies. 


\section{The Realities of Visualizing Earth Sciences Data}

Rhyne, Theresa M., Martin Marietta Technical Services, U.S. Environmental Protection Agency, Scientific Visualization Center, Research Triangle Park, NC 27709

Earth science data visualization is distinguished by the need for:

- Dealing with data sets that are volumetric, time varying, and multi-variant. This includes both simulation data and remote sensing data, such as volume scanning radars which measure reflectiveness, radial velocities, and polarities.

- Dealing with a variety of data gathering systems, including many satellite sensor types, radars, sonar, lidar (laser radar), and discrete observations from airplanes, ships, buoys and balloons. Physical and environmental data are also inferred from census reports and other geographical information sources.

- Dealing with very large data sets. For example, the archive of Geosynchronous Operational Environmental Satellite data contains 120 terabytes, and scientists must access the entire data set to understand climate change. The National Aeronautics and Space Administration's Earth Observing System will generate one terabyte of data per day.

The visual presentation of large amounts of earth sciences data often requires the merging of image processing methods with computer-generated color displays. Frequently there is also a need for the integration of other computational technologies with visualization methods. These include:

- the integration of terabyte or gigabyte distributed earth sciences databases with visualization systems;

- the dual access and simultaneous display of data from geographic information systems tools and visualization systems;

- the design of visualization tools and user interfaces which support the specific needs of policy analysts and regulators;

- the development of collaborative computing tools that allow the integration of multi-disciplinary data (e.g. atmospheric, oceanographic, and geographic) into visualization systems to foster cross-disciplinary exploration and communications.

This presentation will highlight work to address these issues that is underway at the U.S. Environmental Protection Agency's Scientific Visualization Center. 


\section{How to Construct and View Computer-Generated Animation Sequences on your Workstations: Shareware Tools for Working with Compression Files}

Signell, Richard P., U.S. Geological Survey, Geologic Division, Crawford Building, Quissett Campus, Woods Hole, MA 02543

Animation is rapidly emerging as a powerful tool for scientific visualization. A major problem with animation, however, is how to distribute it to other members of the scientific community and to the public. Production of a VHS videotape is the most common solution, since video cassette recorders are commonplace in presentation halls, schools, and the home. It is often desirable to develop animation sequences in a form that may be displayed on a variety of personal computers (MSDOS or Apple Macintosh Operating System) and UNIX-based workstations with the $\mathrm{X}$-windows display environment by using freeware or shareware tools. In this form, the animation sequence may be viewed on a desktop computer and becomes more interactive; the rate of playback can be adjusted, and the frames can be stepped forward or backward. This form also allows widespread dissemination of the data to the global community through Internet tools such as Gopher and Mosaic.

Two of the most popular animation file formats are FLI/FLC (these are formats compatible with Autodesk Animator) and Motion Picture Experts Group (MPEG). Both are compressed file formats specifically designed for animation. The FLI/FLC formats use a relatively simple scheme that essentially stores changes between successive 8-bit (256 color) images. The principal advantage of the FLI/FLC formats is a relatively fast playback rate due to the simplicity of the compression scheme. An additional advantage is that if the original images have the same 256 element color map, then the FLI/FLC formats contain all the information in the original images; the compression scheme is lossless. The MPEG format, by comparison, is a relatively complex scheme that not only uses changes between images but also uses a Joint Photographic Experts Group-like Fourier transform technique to compress the changes in which image information is lost. The advantages of the MPEG format are small file size (often 10 times smaller than FLI/FLC) and the ability to handle 24-bit (16.7 million color) images. The principal disadvantage of MPEG is the relatively slow playback rate relative to FLI/FLC. The construction and playback of both FLI/FLC and MPEG files will be demonstrated by using freeware and shareware tools. 


\section{Issues in the Visualization of Large Terrain Databases}

Stanfill IV, Daniel F., Visualization and Earth Science Applications Group, Image Processing Applications and Development Section, Jet Propulsion Laboratory, California Institute of Technology, Pasadena, CA 91109-8099

It is now common for terrain databases (topography and imagery combined) to require many gigabytes of storage, but most current visualization technologies restrict interactive use of data sets to a few megabytes. This talk will cover issues related to the visualization of large terrain databases. A survey of existing rendering technologies will be given, including strengths and weaknesses of each. In addition, techniques for the integration of graphical information--such as cultural features, atmospheric or subsurface isosurfaces, and seismic data--will be discussed. Finally, user interface issues related to the visualization of such large databases will be covered. 


\section{Visualizing Geographic Data: Integrating a Geographic Information System and Scientific Visualization System}

Stephenson, Mary, North Carolina Supercomputing Center, P.O. Box 12889, Research Triangle Park, NC 27709

Geographic information systems (GIS) are used for the display, manipulation, storage, and spatial analysis of geographic data. The primary spatial analysis technique is to perform map overlay operations where features and attributes from one map layer are combined with those from a second map layer. An example of such an operation is the combination of a soils map with one containing ownership parcels to determine the potential agricultural value of the parcels. The results are typically displayed by creating a thematic map or using statistical or tabular methods. Other types of spatial analysis include buffering, network analyzing, and raster modeling techniques which GISs are unparalleled in performing.

However, many times the results yield more attributes and features than can be analyzed using typical display methods. There is a need to be able to interactively analyze this geographic data using other methods. Scientific visualization is one of the methods that has potential for enhancing the analysis process. By using GIS visualization tools, a user may see new spatial relationships.

To demonstrate the potential of the GIS/visualization combination, a prototype that integrates Application Visualization System (AVS) and ARC/INFO has been developed. This prototype consists of modules developed within the AVS framework using the ARC/INFO Software Development Library (SDL) to directly access ARC/INFO coverages. These modules provide three-dimensional representations of coverages and coverage features as well as provide the ability to perform real-time animations. The modules are available from the anonymous $\mathrm{ftp}$ site of the International AVS Center located at the North Carolina Supercomputing Center in Research Triangle Park, N.C. These modules are currently available on SUN(OS), Digital Equipment Corporation(ULTRIX), and Silicon Graphics Indigo workstations. 


\section{Application of Scientific Visualization Techniques for Analysis of the 1993 Flood on the Mississippi River}

Traub, Lisa M., U.S. Geological Survey, Water Resources Division, 415 National Center, Reston, VA 22092

Scientific visualization techniques were used on a project at the U.S. Geological Survey to analyze and display flood data from the 1993 Mississippi River flood. Channel-bathymetry data and water-velocity data that were measured at various points 2.5 miles upstream and downstream from the highway crossing at Chester, Ill. were processed using Advanced Visual Systems, Inc., Application Visualization System (AVS). The resulting displays were then used to study how the bridge affected velocity vectors and channel scour at the highway crossing.

Computing utility modules or subroutines were used from the public domain module library at the North Carolina Supercomputing Center's International AVS Center to display and analyze the data. These utilities both expand the types of data format AVS can accept and broaden its functionality. Various aspects of AVS, which were learned through the above project, are discussed to help new users of AVS increase their productivity. 


\section{Developing a Three-Dimensional Hydrogeologic Model}

Turner, A. Keith , U.S. Geological Survey, Box 25046, MS 421, Denver, CO 80225; Faunt, Claudia C., U.S. Geological Survey, Box 25046, MS 421, Denver, CO 80225;

D'Agnese, Frank A., U.S. Geological Survey, Box 25046, MS 421, Denver, CO 80225

Geology deals with three-dimensional data. Until recently, computers were of little assistance to three-dimensional data handling and visualization problems. Memory was too expensive, computational speeds were too slow, and graphical display devices had insufficient resolution or were too expensive to produce useful visualizations. About five years ago, a critical performance and cost threshold was crossed and the initial commercial systems to support three-dimensional geological modeling and visualization were announced and demonstrated. Computer hardware and software development trends indicate that even more powerful and faster systems, with more memory and even greater display capabilities, will be available at even lower costs. A combination of these modeling and visualization systems has been used to successfully construct a three-dimensional hydrogeologic model of the Death Valley region of Nevada and California. The study area includes approximately 100,000 square kilometers and extends to depths of 10 kilometers. Geologic conditions are typical of the Basin and Range province; a considerable variety of intrusive and extrusive igneous, sedimentary, and metamorphic rocks have been subjected to several episodes of compressional and extensional deformation.

Modern geological applications require increasingly quantitative and accurate rock-property characterizations within the three-dimensional subsurface environment. This requirement places a special burden on the scientific visualization tools for the following reasons:

- only incomplete, and sometimes conflicting, information is available concerning the dimensions, geometries, and variabilities of the rock units, at all scales of interest;

- the natural subsurface environment is characterized by extremely complex spatial relationships;

- $\quad$ economics prevent sufficiently dense sampling required to resolve all uncertainties; and 
- $\quad$ the relationships between rock property values and rock volumes over which they are being averaged (the scale effect) are usually unknown.

From the data management viewpoint, the subsurface may be best defined with "geo-objects," which belong to different classes. "Sampling-limited" geo-objects include intrusions whose shapes can be progressively better defined by repeated spatial sampling. "Definition-limited" geo-objects include features whose shape and size vary according to some specification, for example, an ore body which changes shape with changes in cut-off grade.

Modeling of the Death Valley region included compilation of various subsurface investigations, resulting in large data volumes. Both sampling-limited and definition-limited classes of geo-objects were used. The modeling and visualization systems supported both the data management and data visualization tasks. No single system provided all the required capabilities. Methods were developed to accept the limited observational data, combine them with the geological experience of the user, and produce conceptual models of the subsurface. Construction of the three-dimensional hydrogeologic framework model was done in the following way:

(1) digitizing geologic maps, cross-sections, and topographic elevations and placing them accurately within three-dimensional space;

(2) attributing geologic maps and cross-sections with hydrogeologic characteristics;

(3) extracting $x, y$, and $z$ coordinates defining fault locations and tops of the hydrogeologic units along the cross-sections and the ground-surface;

(4) defining three-dimensional surfaces by interpolating between cross-sections with sophisticated gridding algorithms which incorporated fault information and ground-surface data;

(5) constructing the three-dimensional hydrogeologic framework using geologic rules to relate the previously developed surfaces; and

(6) displaying and evaluating the resulting model.

Once a suitable subsurface geologic framework was defined, the model was enhanced with additional information concerning surficial conditions and processes. Remote sensor imagery, precipitation data, soil surveys, and water-use information were combined to identify recharge and discharge patterns. This enhanced model supplied the necessary information to appropriate numerical ground-water flow 
models. These linkages required the creation of finite-difference meshes by resampling the database and the spatial hydrogeologic model.

The ability to rapidly create and manipulate three-dimensional images can materially speed up the geoscientist's understanding of the subsurface environment. From a practical and efficiency point-of-view, methods for assessing the "usefulness" or "reasonableness" of the subsurface characterizations must be available. Without them, the investigator cannot make rational decisions concerning the completeness or adequacy of the conceptual model. Three-dimensional spatial visualization helps in making such assessments. 


\section{GeoMedia2: A Multimedia Educational System on Global Environmental Change for Middle School Students}

Wiltshire, Denise A., U.S. Geological Survey, Information Systems Division, 801 National Center, Reston, VA 22092;

Ferrigno, Carmelo F., U.S. Geological Survey, Information Systems Division, 804 National Center, Reston, VA 22092

In August 1992, the U.S. Geological Survey began the second phase of a research and development project to assess the effectiveness of hypermedia technology in teaching earth science topics to middle school students. This phase of the project focuses on developing a hypermedia educational system on global environmental change. The new prototype system is patterned after the GeoMedia educational system that was developed by the U.S. Geological Survey during 1991-92. (The GeoMedia prototype contains modules on the water cycle, earthquakes, and maps.) The global change educational system (GeoMedia2) was produced using hypermedia computer techniques, which are based on the nonsequential arrangement of information in the forms of text, graphics, animations, and sounds. The application was designed for Apple ${ }^{\circledR}$ Macintosh ${ }^{\circledR}$ computers and developed using MacroMind $₫$ Director $^{\mathrm{TM}}$ authoring software, which is produced by Macromedia, Inc. The three modules contained within GeoMedia2 include:
(1) Carbon cycle,
(2) Greenhouse Effect, and
(3) Time \& Change.

GeoMedia (volume 1) was distributed from October 1992-December 1993 on digital compact disc to teachers interested in participating in this research and development project. Preliminary results of the evaluation of GeoMedia (volume 1) indicate the following:

(1) The material is appropriate for grades 4-8.

(2) Student interest in the earth sciences was increased using GeoMedia.

(3) Despite the limitations of system performance on minimally-configured Apple Macintosh systems, students responded favorably to the hypermedia format.

(4) The visualization of complex earth processes as animations facilitated the learning process. 
The project team began distribution of GeoMedia2 in January 1994 and plans to seek teacher and student evaluation comments for the next year. The project team will continue to analyze teacher evaluations to further determine the effectiveness of hypermedia technology for teaching earth science and to enhance the design of future educational software. 


\section{Visualization of Marine Scientific Data}

Wright, Evelyn L., U.S. Geological Survey, Crawford Building, Quissett Campus, Woods Hole, MA 02543;

Signell, Richard P., U.S. Geological Survey, Crawford Building, Quissett Campus, Woods Hole, MA 02543;

Coleman, Dwight F., U.S. Geological Survey, Crawford Building, Quissett Campus, Woods Hole, MA 02543

At the U.S. Geological Survey, providing visualization support for marine scientific projects is challenging because of limited money, the variety of projects requiring visualization, and the diversity of hardware platforms that the scientists use. We use Application Visualization System (AVS), from Advanced Visual Systems, Inc., Waltham, Mass., a modular, extensible, multiplatform software system that is adaptable to a wide range of applications for scientific visualization. Examples of recent work will be presented.

AVS was used to interactively visualize earthquake hypocenters in three-dimensional space, enabling the interpretation of the geometry of interacting slabs of North American and Caribbean lithosphere near the Puerto Rico plate boundary zone. After experimenting with color, symbol size, perspective, and other visualization variables, we used AVS to produce a videotape that shows the plate interaction zone as if one were flying around it.

Visualization of a three-dimensional circulation model of Massachusetts Bay required developing unique AVS modules for entering data, showing cross-sections, and labeling time and direction. We produced a videotape that contrasts modeled time-dependent plume behavior at a present sewage outfall site with that at a proposed site.

Both videotapes will be shown at the workshop. We will also show work in progress on visualizing seafloor sedimentary environments in Massachusetts Bay. These AVS applications demonstrate that scientific visualization is useful for presenting data for decisionmaking as well as for aiding research. 


\section{Using Scientific Visualization Techniques to Portray Land Surfaces}

Young, Paul M., U.S. Geological Survey, National Mapping Division, 560

National Center, Reston, VA 22092

The computer display has now joined the traditional paper map as a medium for depicting the Earth's surface. Using scientific visualization concepts and techniques, cartographers and other earth scientists are changing the way that they use spatial data to view landforms. A paper map can portray only a limited number of features and is further limited to a specific scale and time. Usually, portraying changes to landforms over time requires either multiple maps or a map with a design so complex that it can be difficult to interpret. With new technology and computerreadable spatial data, map users can now view the changing land surface in three dimensions and can control the perspective, scale, time, and content of the display. For example, a forester can watch an animation that shows an area before and after trees are cut down and then year by year as seedlings grow. The cartographic sources for these unconventional maps can be remotely sensed images, digitized maps, and point data. Urban planners, resource managers, environmental engineers, or even people looking for potential vacation spots can use cartographic data and these scientific visualizations techniques. 